\title{
Kecocokan Jenis Inang dan Pemberian Pupuk Kandang terhadap Pertumbuhan Semai Cendana (Santalum album L. )
}

\author{
Host's Species Matching Plants and Natural Fertilizer To The Growth of Sandalwood \\ Seedling (Santalum album L.)
}

\section{Kuswanto}

Jurusan Budidaya Hutan Fakultas Kehutanan Universitas Gadjah Mada Yogyakarta

\begin{abstract}
The purpose of this research was find out the effects of three host plants and three levels of natural fertilizer on sandalwood seedling growth. This natural relationship between host plant and sandalwood seedling was conducted recognize the characteristic of seedling growth was studied. The parameters were height, diameter, and haustoria number.

The research was conducted in factorial experiment arranged in CRD. The treatment consisted of two factors, namely effect of host plant and stable fertilizer. The first factor consisted four kinds of host plants were : a/ control; b/ Cabe rawit ; c/ Turi; and d/ Lamtoro, while the second factor were four levels of stable fertilizer : $a /$ control; $b / 200$ g/pot; c/ $300 \mathrm{~g} /$ pot, and d/ 400g/pot. Three replicates was employed in the research.

The result of the research indicated that most of different host plant and stable fertilizer treatments were significant effect on sandalwood seedling growth. After five months, the highest growth of Sandalwood seedling treatment with turi and stable fertilizer $400 \mathrm{~g} / \mathrm{pot}$ was $44.92 \mathrm{~cm}$, and $38.41 \mathrm{~cm}$ with host plant cabe rawit and stable fertilizer $300 \mathrm{~g} / \mathrm{pot}$. While the lowest was $12.80 \mathrm{~cm}$ produced by control (without host plant and fertilizer ). The diameter growth of sandalwood seedling treatment with turi and stable fertilizer 400 g/pot was $3,09 \mathrm{~mm}$, and $3,30 \mathrm{~mm}$ with cabe rawit and stable fertilizer $400 \mathrm{~g} /$ pot. The houstoria number of sandalwood seedling treatment with turi was 75 and 71 with cabe rawit. In terms of determined the relationship between Sandalwood and its host plants were first turi , second cabe rawit, and lamtoro gung.
\end{abstract}

Keyword : Relationship, sandalwood, turi, cabe rawit, lamtoro

Diterima: 09 Juni 2004, disetujui: 28 Juli 2004

\section{Pendahuluan}

Cendana (Santalum album L.) merupakan salah satu jenis tanaman terpilih untuk HTI di wilayah Indonesia Timur. Jenis tanaman ini mempunyai nilai ekonomis yang tinggi karena kandungan minyak yang berbau harum pada kayunya, mudah tumbuh pada tempat-tempat yang kurang subur, bahkan mampu tumbuh pada lahan-lahan yang kurus berbatu dan pada daerah yang beriklim kering (Sipayung, 1983; Soekotjo \& Joedodibroto, 1970; Anonim, 1979). Kayu cendana mempunyai struktur yang halus dan homogen dengan warna yang masif sehingga sangat baik untuk bahan pembuat patung dan kerajinan. Potensi pemanfaatan seperti itu tidak menuntut persyaratan diameter dan panjang, sehingga kayu-kayu berdiameter kecilpun sudah dapat dimanfaatkan. Kayu dan minyak cendana merupakan komoditas yang bernilai ekonomi tinggi baik pada pasar nasional maupun internasional, dan oleh karenanya sangat potensial sebagai penyumbang devisa negara dan pendapatan daerah.

Saat ini tanaman cendana di daerah pusat-pusat pertanaman semakin terancam punah oleh karena tingginya intensitas 
pembalakan dan pencurian pohon yang tidak diimbangi dengan usaha permudaan. Rendahnya upaya permudaan pertanaman cendana disebabkan karena terbatasnya pengetahuan tentang teknik budidayanya, sehingga minat masyarakat menjadi rendah. Hal ini mengakibatkan semakin tidak seimbangnya antara laju pembalakan dan pencurian pohon cendana dan permudaannya.

Selain faktor-faktor fisik yang mampu mempengaruhi pertumbuhannya, cendana mempunyai sifat semi-parasit serta pertumbuhan yang lambat, sehingga memerlukan strategi permudaan dan penanaman yang tepat. Ketergantungan pada inang yang belum tergantikan dengan substitusi hara atau jasad simbiotik (Sumardi, 1992; Kuswanto, 1989), merupakan kendala dalam menyediakan bibit yang sehat dalam jumlah yang banyak. Penelitian yang telah dilakukan sebagian besar bertujuan untuk mengetahui jenis-jenis tanaman yang cocok sebagai inang cendana. Penambahan unsur hara kedalam medium tumbuh juga sangat dimungkinkan, karena merupakan strategi dalam silvikultur untuk meningkatkan penyerapan unsur hara oleh akar tanaman. Meskipun demikian, di lapangan masih ditemukan kendala untuk memenuhi kebutuhan bibit dalam jumlah yang besar dan memenuhi standar.

Penelitian ini diarahkan untuk mengetahui keeratan hubungan antara cendana dan inang terpilih, yaitu Cabe rawit hijau (Capsicum frustescen), Turi (Sesbania grandiflora), Lamtoro gung (Leucaene leucocephala). Selain itu pengaruh pupuk kandang terhadap keeratan hubungan ini juga dipelajari.

\section{Bahan Dan Metode}

\section{Bahan}

Kecambah cendana dipilih yang tingginya sama, kecambah tanaman inang berupa turi, cabe rawit, dan lamtoro gung, semuanya berumur 1 minggu. Pupuk kandang yang digunakan berasal dari kotoran sapi.

\section{Analisis}

Rancangan percobaan yang digunakan adalah rancangan acak lengkap (RAL) dengan kombinasi perlakuan secara faktorial. Faktor perlakuan ada dua yaitu tanaman inang dan pemupukan. Perlakuan tanaman inang sendiri terdiri atas penggunaan jenis-jenis cabe rawit $\left(I_{1}\right)$, turi $\left(I_{2}\right)$ dan lamtoro $\left(I_{3}\right)$. Sedangkan faktor pemupukan terdiri $200 \mathrm{~g} /$ pot $\left(\mathrm{P}_{1}\right), 300 \mathrm{~g} /$ pot $\left(\mathrm{P}_{2}\right)$ dan $400 \mathrm{~g} /$ pot $\left(\mathrm{P}_{3}\right)$. Masing-masing perlakuan dilengkapi dengan kontrol (masingmasing $\mathrm{I}_{0}$ dan $\mathrm{P}_{0}$ ) sebagai pembanding dan keseluruhan perlakuan diulang 3 kali. Tanggapan perlakuan diukur menggunakan parameter tinggi semai, diameter semai, dan jumlah haustoria yang terbentuk pada akar tanaman inang.

Analisis hasil dilakukan dengan menggunakan analisis varians, dan apabila hasil uji keragaman menunjukkan adanya beda nyata, pengujian dilanjutkan dengan uji Duncan New Multiple Range Test (DMRT) dengan taraf uji 0,05 .

\section{Hasil Dan Pembahasan}

Tanaman cendana bersifat semi parasit sehingga tanaman ini mempunyai strategi tertentu dalam pertumbuhannya. Cendana tidak membentuk akar rambut dalam jumlah yang cukup, sehingga sulit melaksanakan fungsinya untuk menyerap hara secara langsung dari dalam tanah. Kondisi demikian menyebabkan cendana menunjukkan tanggapan yang berbeda dengan tanaman lain pada umumnya apabila sifat semiparasit tersebut tidak dipenuhi terutama

\section{Tinggi Semai}

Tabel 1 menunjukkan bahwa terdapat perbedaan tanggapan pertumbuhan tinggi semai cendana yang nyata antara perlakuan menggunakan inang turi dan cabe rawit yang ditambah pupuk $\left(\mathrm{I}_{2} \mathrm{P}_{1}, \mathrm{I}_{2} \mathrm{P}_{2}, \mathrm{I}_{2} \mathrm{P}_{3}, \mathrm{I}_{1} \mathrm{P}_{1}, \mathrm{I}_{1} \mathrm{P}_{2}, \mathrm{I}_{1} \mathrm{P}_{3}\right)$ dengan perlakuan tanpa inang pada berbagai aras pupuk. Hasil ini sejalan dengan peneliti terdahulu yang menggunakan tanaman inang cabe rawit dan penambahan pupuk $\mathrm{P}$ akan 
memperbaiki pertumbuhan tinggi semai cendana (Sumardi, 1992; Dharsono, 1992).

Apabila dibandingkan dengan perlakuan yang lain, perlakuan dengan inang turi dan pupuk kandang $400 \mathrm{~g} /$ pot $\quad\left(\mathrm{I}_{2} \mathrm{P}_{3}\right)$ mencapai tinggi terbaik yaitu $44,92 \mathrm{~cm}$, sedangkan perlakuan kontrol $\left(\mathrm{I}_{0} \mathrm{P}_{0}\right)$ hanya mencapai tinggi $12,80 \mathrm{~cm}$.

Sumardi (1992) mengemukakan bahwa tanaman cendana dengan semua perlakuan yang diberikan dalam penelitiannya, termasuk pemupukan fosfat, yang ditanam tanpa tanaman inang pada umur 6 bulan daunnya berwarna kekuningan dan berguguran meninggalkan 2-3 pasang pucuk. Secara fisiologis pengaruh gejala tersebut merupakan sebagian gejala tanaman yang kekurangan unsur hara.

\section{Diameter Semai Cendana}

Tabel 2. menunjukan bahwa perlakuan semai cendana yang ditanam bersama-sama inang cabe berpengaruh baik terhadap pertumbuhan diameter semai cendana yang ditanam bersama inang cabe dengan dosis pupuk kandang $400 \mathrm{~g} /$ pot $\left(\mathrm{I}_{1} \mathrm{P}_{3}\right)$ mencapai diameter tertinggi yaitu sebesar $3,30 \mathrm{~mm}$, diikuti oleh perlakuan semai cendana yang ditanam bersama inang cabe dengan dosis pupuk kandang $300 \mathrm{~g} /$ pot $\left(\mathrm{I}_{1} \mathrm{P}_{2}\right)$ yaitu sebesar $3,20 \mathrm{~mm}$, sedangkan kontrolnya $\left(\mathrm{I}_{0} \mathrm{P}_{0}\right)$ hanya mencapai 2,00 $\mathrm{mm}$. Tabel 2 juga menyajikan uji lanjut DMRT kombinasi perlakuan semai cendana yang ditanam bersama beberapa jenis tanaman inang dan pemberian dosis pupuk kandang.

Tabel 1. Hasil uji DMRT rata-rata tinggi $(\mathrm{cm})$ semai cendana umur 5 bulan dengan perlakuan jenis inang dan dosis pupuk $(\mathrm{P}, \mathrm{a}<0,05)$

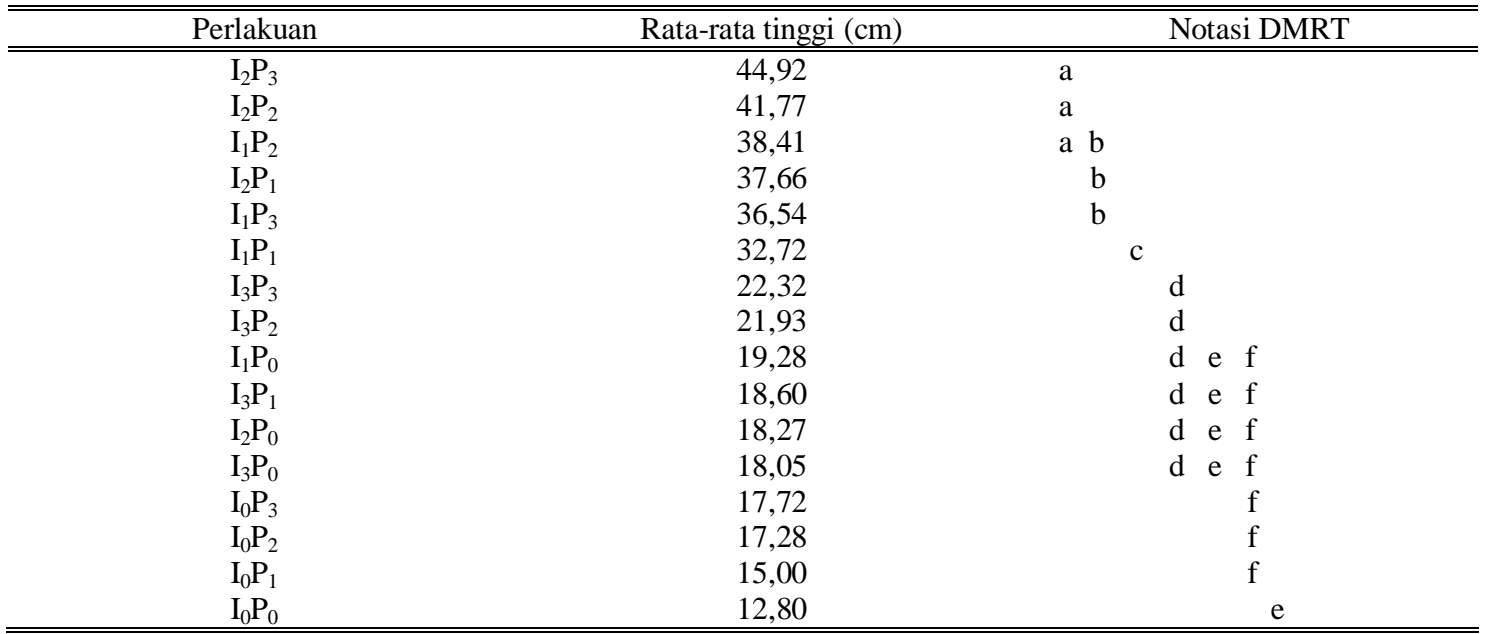

Keterangan : Huruf yang sama tidak berbeda nyata pada taraf uji 5\%

$$
\begin{array}{ll}
\text { I0P }=\text { S.album } \text { (kontrol) } \\
\text { I0P1 } & =\text { S.album }+ \text { pupuk } 200 \mathrm{~g} \\
\text { I0P2 } & =\text { S.album }+ \text { pupuk } 300 \mathrm{~g} \\
\text { I0P3 } & =\text { S.album }+ \text { pupuk } 400 \mathrm{~g} \\
\text { I1P0 } & =\text { S.album }+ \text { C. frustescens } \\
\text { I1P1 } & =\text { S.album }+ \text { C. frustescens }+ \text { pupuk } 200 \mathrm{~g} \\
\text { I1P2 } & =\text { S.album }+ \text { C. frustescens }+ \text { pupuk } 300 \mathrm{~g} \\
\text { I1P3 } & =\text { S.album }+ \text { C. frustescens }+ \text { pupuk } 400 \mathrm{~g} \\
\text { I2P0 } & =\text { S.album }+ \text { S. grandiflora } \\
\text { I2P1 } & =\text { S.album }+ \text { S. grandiflora }+ \text { pupuk } 200 \mathrm{~g} \\
\text { I2P2 } & =\text { S.album }+ \text { S. grandiflora }+ \text { pupuk } 300 \mathrm{~g} \\
\text { I2P3 } & =\text { S.album }+ \text { S. grandiflora }+ \text { pupuk } 400 \mathrm{~g} \\
\text { I3P0 } & =\text { S.album }+ \text { L.leucocephala } \\
\text { I3P1 } & =\text { S.album }+ \text { L. leucocephala }+ \text { pupuk } 200 \mathrm{~g} \\
\text { I3P2 } & =\text { S.album }+ \text { L. leucocephala }+ \text { pupuk } 300 \mathrm{~g} \\
\text { I3P3 } & =\text { S.album }+ \text { L. leucocephala }+ \text { pupuk } 400 \mathrm{~g}
\end{array}
$$


Kecocokan Jenis Inang dan Pemberian Pupuk Kandang terhadap Semai Cendana

Tabel 2. Hasil uji DMRT rata-rata Diameter $(\mathrm{mm})$ semai cendana umur 5 bulan dengan perlakuan jenis inang dan dosis pupuk $(\mathrm{P}, \mathrm{a}<0,05)$

\begin{tabular}{|c|c|c|c|c|}
\hline Perlakuan & Rata-rata diameter (mm) & & & Notasi DMRT \\
\hline$\overline{\mathrm{I}_{1} \mathrm{P}_{3}}$ & 3,30 & $\overline{\mathrm{a}}$ & & \\
\hline $\mathrm{I}_{1} \mathrm{P}_{2}$ & 3,20 & $\mathrm{a}$ & & \\
\hline $\mathrm{I}_{2} \mathrm{P}_{3}$ & 3,09 & $\mathrm{a}$ & & \\
\hline $\mathrm{I}_{1} \mathrm{P}_{1}$ & 3,01 & $\mathrm{a}$ & & \\
\hline $\mathrm{I}_{2} \mathrm{P}_{2}$ & 2,94 & $\mathrm{~b}$ & & \\
\hline $\mathrm{I}_{2} \mathrm{P}_{1}$ & 2,88 & $\mathrm{~b}$ & $\mathrm{c}$ & \\
\hline $\mathrm{I}_{2} \mathrm{P}_{0}$ & 2,39 & & $\mathrm{c}$ & \\
\hline $\mathrm{I}_{3} \mathrm{P}_{2}$ & 2,33 & & $\mathrm{c}$ & $\mathrm{d}$ \\
\hline $\mathrm{I}_{3} \mathrm{P}_{3}$ & 2,29 & & & $\mathrm{~d}$ \\
\hline $\mathrm{I}_{3} \mathrm{P}_{1}$ & 2,22 & & & d \\
\hline $\mathrm{I}_{3} \mathrm{P}_{0}$ & 2,19 & & & d \\
\hline $\mathrm{I}_{1} \mathrm{P}_{0}$ & 2,19 & & & $\mathrm{~d}$ \\
\hline $\mathrm{I}_{0} \mathrm{P}_{3}$ & 2,11 & & & $\mathrm{~d}$ \\
\hline $\mathrm{I}_{0} \mathrm{P}_{2}$ & 2,11 & & & $\mathrm{e}$ \\
\hline $\mathrm{I}_{0} \mathrm{P}_{1}$ & 2,06 & & & $\mathrm{e}$ \\
\hline $\mathrm{I}_{0} \mathrm{P}_{0}$ & 2,00 & & & $\mathrm{e}$ \\
\hline
\end{tabular}

Keterangan : Huruf yang sama tidak berbeda nyata pada taraf uji $5 \%$

$\begin{array}{ll}\text { I0P } & =\text { S.album (kontrol) } \\ \text { I0P1 } & =\text { S.album }+ \text { pupuk } 200 \mathrm{~g} \\ \text { I0P2 } & =\text { S.album }+ \text { pupuk } 300 \mathrm{~g} \\ \text { I0P3 } & =\text { S.album }+ \text { pupuk } 400 \mathrm{~g} \\ \text { I1P0 } & =\text { S.album }+ \text { C. frustescens } \\ \text { I1P1 } & =\text { S.album }+ \text { C. frustescens }+ \text { pupuk } 200 \mathrm{~g} \\ \text { I1P2 } & =\text { S.album }+ \text { C. frustescens }+ \text { pupuk } 300 \mathrm{~g} \\ \text { I1P3 } & =\text { S.album }+ \text { C. frustescens }+ \text { pupuk } 400 \mathrm{~g} \\ \text { I2P0 } & =\text { S.album }+ \text { S. grandiflora } \\ \text { I2P1 } & =\text { S.album }+ \text { S. grandiflora }+ \text { pupuk } 200 \mathrm{~g} \\ \text { I2P2 } & =\text { S.album }+ \text { S. grandiflora }+ \text { pupuk } 300 \mathrm{~g} \\ \text { I2P3 } & =\text { S.album }+ \text { S. grandiflora }+ \text { pupuk } 400 \mathrm{~g} \\ \text { I3P0 } & =\text { S.album }+ \text { L.leucocephala } \\ \text { I3P1 } & =\text { S.album }+ \text { L. leucocephala }+ \text { pupuk } 200 \mathrm{~g} \\ \text { I3P2 } & =\text { S.album }+ \text { L. leucocephala }+ \text { pupuk } 300 \mathrm{~g} \\ \text { I3P3 } & =\text { S.album }+ \text { L. leucocephala }+ \text { pupuk } 400 \mathrm{~g}\end{array}$

Tabel 2 menunjukkan bahwa pengaruh perlakuan semai cendana yang ditanam bersama-sama inang cabe berbeda nyata dibandingkan dengan perlakuan penanaman bersama-sama inang lain. Hasil ini serupa dengan hasil yang diperoleh Sumardi (1992). Dalam laporan penelitiannya, peneliti ini mengemukakan bahwa penambahan unsur $\mathrm{F}$ (fosfor) dalam bentuk superfosfat dengan takaran 60, 160 dan $540 \mathrm{mg}$ ekuivalen $\mathrm{P}$ per pot tidak memberikan stimulasi terhadap pertumbuhan anakan cendana. Hal ini terjadi baik pada pertumbuhan meninggi maupun berat kering tanaman berumur 6 bulan.

Hasil serupa dijumpai pada penelitian Barret (1985) yang menemukan gejala serupa ketika melakukan pemupukan anakan cendana dengan menggunakan pupuk $\mathrm{N}$ berupa amonium sulfat dan pupuk daun. Pada umur 12 bulan tanaman cendana tersebut mengalami klorosis dan mati pucuk.

Hasil-hasil diatas membuktikan bahwa semai cendana tanpa inang tidak mampu memanfaatkan sumber hara di dalam medium tumbuhnya.

\section{Jumlah Haustoria Semai Cendana}

Perbedaan tanggapan pertumbuhan semai cendana yang sangat nyata antara semai cendana yang ditanam bersama inang dengan semai cendana yang ditanam tidak bersama inang dapat diduga karena adanya peranan 
inang dalam memberikan pasokan nutrisi bagi semai cendana. Sistem perakaran cendana yang miskin rambut akar memerlukan kehadiran inang untuk pertumbuhannya. Besarnya peranan inang terhadap pertumbuhan semai cendana tidak lepas dari kelancaran pasokan hara lewat akar. Hubungan yang terjadi antara akar semai cendana dengan akar tanaman inang dilakukan melalui kontak haustorianya.
Haustoria merupakan alat yang digunakan oleh akar cendana untuk mengambil zat makanan yang diserap dari inangnya (Hamzah, 1976). Untuk mengetahui pengaruh tanaman inang dan pemberian dosis pupuk kandang berbeda nyata atau tidak, maka dilakukan uji lanjut dengan menggunakan metode DMRT yang hasilnya disajikan pada Tabel 3.

Tabel 3. Hasil uji DMRT rata-rata Jumlah Haustoria semai cendana umur 5 bulan dengan perlakuan jenis inang dan dosis pupuk $(\mathrm{P}, \mathrm{a}<0,05)$

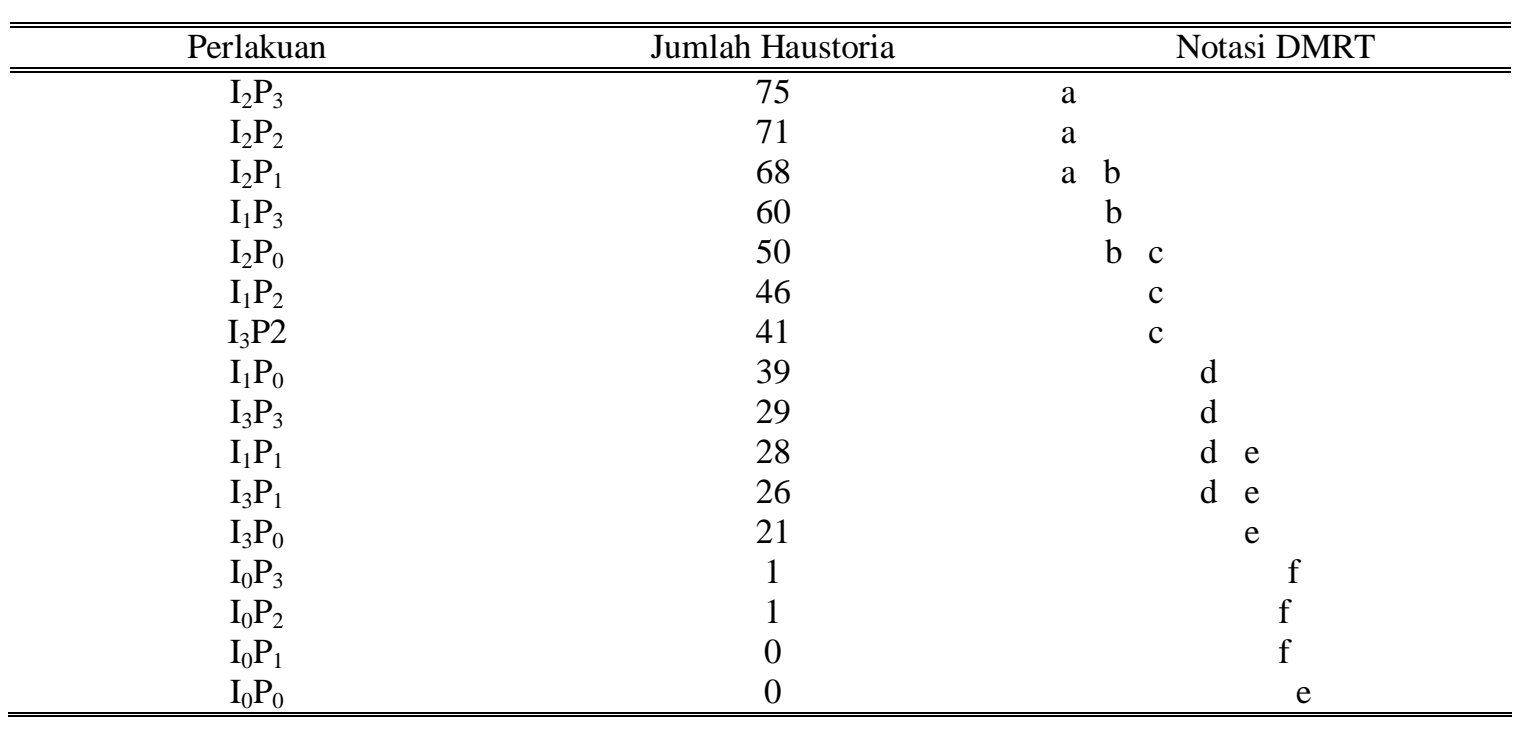

Keterangan : Huruf yang sama tidak berbeda nyata pada taraf uji 5\%

$$
\begin{array}{ll}
\text { IOP }=\text { S.album } \text { (kontrol) } \\
\text { IOP1 } & =\text { S.album }+ \text { pupuk } 200 \mathrm{~g} \\
\text { IOP2 } & =\text { S.album }+ \text { pupuk } 300 \mathrm{~g} \\
\text { IOP3 } & =\text { S.album }+ \text { pupuk } 400 \mathrm{~g} \\
\text { I1P0 } & =\text { S.album }+ \text { C. frustescens } \\
\text { I1P1 } & =\text { S.album }+ \text { C. frustescens }+ \text { pupuk } 200 \mathrm{~g} \\
\text { I1P2 } & =\text { S.album }+ \text { C. frustescens }+ \text { pupuk } 300 \mathrm{~g} \\
\text { I1P3 } & =\text { S.album }+ \text { C. frustescens }+ \text { pupuk } 400 \mathrm{~g} \\
\text { I2P0 } & =\text { S.album }+ \text { S. grandiflora } \\
\text { I2P1 } & =\text { S.album }+ \text { S. grandiflora }+ \text { pupuk } 200 \mathrm{~g} \\
\text { I2P2 } & =\text { S.album }+ \text { S. grandiflora }+ \text { pupuk } 300 \mathrm{~g} \\
\text { I2P3 } & =\text { S.album }+ \text { S. grandiflora }+ \text { pupuk } 400 \mathrm{~g} \\
\text { I3P0 } & =\text { S.album }+ \text { L.leucocephala } \\
\text { I3P1 } & =\text { S.album }+ \text { L. leucocephala }+ \text { pupuk } 200 \mathrm{~g} \\
\text { I3P2 } & =\text { S.album }+ \text { L. leucocephala }+ \text { pupuk } 300 \mathrm{~g} \\
\text { I3P3 } & =\text { S.album }+ \text { L. leucocephala }+ \text { pupuk } 400 \mathrm{~g}
\end{array}
$$

Tabel 3. menunjukkan bahwa pengaruh perlakuan semai cendana yang ditanam bersama-sama inang turi berbeda nyata dibandingkan dengan perlakuan penanaman bersama-sama inang lainnya. Pengaruh perlakuan inang turi dan dosis pupuk kandang tertinggi terhadap terbentuknya jumlah haustoria dicapai oleh perlakuan semai cendana yang ditanam bersama inang turi dan dosis pupuk kandang $400 \mathrm{~g} /$ pot $\left(\mathrm{I}_{1} \mathrm{P}_{3}\right)$ yaitu sejumlah 75 , sedangkan kontrol $\left(\mathrm{I}_{0} \mathrm{P}_{0}\right)$ tidak terbentuk haustoria sama sekali. Pada semua dosis pemupukan, cendana yang ditanam bersama $I_{1}$ memberikan respon yang sangat 
baik dalam pembentukan haustoria. Jumlah haustoria pada semai cendana yang ditanam dengan inang jauh lebih besar dari pada semai cendana yang ditanam tidak bersama inang. Untuk cendana yang tidak ditanam bersama inang meskipun digunakan dosis pupuk $400 \mathrm{~g} / \mathrm{pot}$, pembentukan haustoria tetap sangat rendah. Ini berarti bahwa cendana yang ditanam tanpa inang tidak dapat berkembang dengan baik. Dalam penelitian Sumardi (1992) dilaporkan bahwa haustoria cendana yang terbentuk tanpa inang mencengkeram bendabenda keras disekitarnya (butir-butir tanah dan akar tanaman cendana sendiri) sehingga tidak mampu menyediakan pasokan hara yang cukup untuk keperluan proses metabolisme dalam pertubuhan cendana.

\section{Kesimpulan}

Berdasarkan hasil pengamatan, analisis data dan pembahasan dapat diketahui perlakuan cendana + turi + pupuk $400 \mathrm{~g}\left(\mathrm{I}_{2} \mathrm{P}_{3}\right)$ merupakan kombinasi perlakuan yang paling baik untuk pertumbuhan semai cendana dengan capaian tinggi rata-rata $44,92 \mathrm{~cm}$ dan jumlah haustoria 75. Sedangkan pertumbuhan diameter terbaik rata-rata $3,30 \mathrm{~mm}$ diperoleh pada perlakuan cendana + cabe rawit + pupuk $400 \mathrm{~g}$ $\left(\mathrm{I}_{1} \mathrm{P}_{3}\right)$. Dengan demikian dapat disimpulkan bahwa jenis inang dan dosis pupuk kandang berpengaruh nyata terhadap pertumbuhan semai cendana.

\section{Daftar Pustaka}

Anonim, 1979. Silvikultur Khusus. Cet. Ke 6. Bagian Penerbitan Yayasan Pembina Fakultas Kehutanan UGM. Yogyakarta.

Dharsono, H. 1992. Pengaruh Inokulasi Mikoriza VA dan Aras Pemupukan Fosfor terhadap Ketergantungan Semai Cendana (Santanum Ketergantungan Semai Cendana (Santanum
album L.) pada Inangnya. Skripsi. Tidak dipublikasikan. Fakultas Kehutanan UGM. Yogyakarta.

Barrett, 1985. Santalum album (Indian Sandalwood) Literature Review. Report Number. Mulga Research Centre. Western Australian Institute of Technology. Bentley, WA 6102.

Hamzah, Z. 1976. Sifat Silvika dan Silvikultur Cendana (Santalum Album L.) di Pulau Timor. Lembaga Penelitian Hutan, Bogor.

Kuswanto, 1989. Peranan Inokulasi Spora dan Tanaman Inang Pada Pertumbuhan Semai Cendana (Santalum Album L.) Laporan Proyek DPP UGM, Yogyakarta.

Sipayung, O.A. 1983. Laporan Perjalanan Studi Perbandingan Cendana Ke India. Dinas Kehutanan Propinsi Daerah Tingkat I Nusa Tenggara Timur.

Soekotjo and Joedodibroto, H. 1970. Beberapa Catatan tentang Kayu Cendana ( Santalum album L.). Seksi Flora Pohon-pohonan Fakultas Kehutanan UGM. Yogyakarta

Sumardi, 1992. Pengaruh Peningkatan Hara Melalui Pemupukan dan Inokulasi Mikoriza terhadap Sifat Parasit Akar Semai Cendana (Santanum album L.). Laporan. Tidak diterbitkan. Fakultas Kehutanan UGM. Yogyakarta. 